\title{
Tracking invasive rat movements with a systemic biomarker
}

\author{
Alysha Bagasra ${ }^{1, *}$, Helen W. Nathan ${ }^{1}$, Mark S. Mitchell ${ }^{2}$, James C. Russel1 ${ }^{1,3}$ \\ ${ }^{1}$ School of Biological Sciences, University of Auckland, Private Bag 92019, Auckland 1142 \\ ${ }^{2}$ Biosecurity, Environmental Services Unit, Auckland Council, Private Bag 92300, Auckland 1142 \\ ${ }^{3}$ Department of Statistics, University of Auckland, Private Bag 92019, Auckland 1142 \\ *Author for correspondence (Email: abag014@aucklanduni.ac.nz) \\ Current address: Ministry for Primary Industries, 25 The Terrace, Wellington 6011
}

Published online: 12 January 2016

\begin{abstract}
Invasive rats can be capable swimmers, able to cross substantial water channels of hundreds of metres to colonise islands. This dispersal capability puts at risk islands close enough to infested areas for rats to reach unassisted. When reinvasion rates are high, biosecurity surveillance on islands might be supported by source population control to prevent re-establishment. However, biosecurity surveillance can only detect reinvading rats when they arrive and the source of reinvading rats might remain unknown. In order to validate hypothesised source sites we used the biomarker Rhodamine B to detect water crossings by ship rats (Rattus rattus) from Great Barrier Island to two neighbouring island groups where eradications had been attempted in the past but were subject to high levels of reinvasion. We detected Rhodamine B in rats dispersing to both island sites, confirming the dispersal of rats across the water gaps, and confirming the hypothesised source sites where additional rat control may be warranted. Chemical markers provide a cost-effective tool to label individuals and determine point sources of origin, most powerfully in situations where dispersal is happening over a scale of weeks.
\end{abstract}

Keywords: biomarker, Great Barrier Island, New Zealand, rat, Rattus rattus, reinvasion, Rhodamine B.

\section{Introduction}

Invasive rats are one of the most prominent ecological problems in many ecosystems worldwide, particularly oceanic islands (Atkinson 1985). Due to their isolation, islands tend to support rare endemic species that cannot thrive elsewhere due to the detrimental impacts of human activities and introduced species (Towns \& Broome 2003). In New Zealand, along with other invasive small mammals, three species of rats-ship rats (Rattus rattus), Norway rats (Rattus norvegicus) and kiore (Rattus exulans) - have been harmful to native species and ecosystems (Towns \& Broome 2003; Towns et al. 2006). All rat species can be transported to islands via humans on water vessels. Analysis has also revealed that rats are capable of dispersal and reinvasion by swimming. Ship rats reinvaded Motutapere and Tawhitinui islands, swimming a distance of 500 $\mathrm{m}$ to do so (Clout \& Russell 2006). Kiore are not known to be as adept swimmers as other rat species with studies showing that they orient poorly towards land and have a mean swimming distance of only $66 \mathrm{~m}$ (Russell et al. 2008b). Eradication of rats and other invasive species to create pest-free sanctuaries has proved a successful conservation management approach on uninhabited islands of varying sizes (Howald et al. 2007). However, reinvasion after eradication is a constant threat to the long term efficacy of island sanctuaries for conservation (Clout \& Russell 2006) such that biosecurity surveillance is now an integral part of eradication planning (Russell et al. 2008a; Bassett et al. 2016).

Rhodamine $\mathrm{B}(\mathrm{RB})$ is a pink coloured, non-toxic dye that has been widely used as a bait marker due to its incorporation and subsequent persistence in keratinous tissue (Fisher 1999). Upon ingestion, $\mathrm{RB}$ can stain a variety of tissues and excretory products, including the gastrointestinal (GI) tract, systemic and internal tissues (Weerakoon et al. 2013). RB can be detected as a maroon colour in ambient light and bright orange under ultraviolet (UV) light in hair and gut (Weerakoon et al. 2013), with keratinous tissue (hair) staining having superior persistence compared with gut and excreta staining (Fisher 1999). Fluorescence microscopy techniques have shown higher sensitivity, detecting smaller doses of RB in hair than detected under ambient or UV light (Fisher 1999; Weerakoon et al. 2013). Vibrissae (whiskers) are useful because they are highly vascularised, thus exposed to circulating RB, and they have a shorter resting phase than other hair types which allows $\mathrm{RB}$ marking to grow out of the bulb, facilitating detection (Purdey et al. 2003; Weerakoon et al. 2013). RB marking is seen as a bright, orange fluorescent band or series of bands along the shaft of the whisker (Fisher 1999; Purdey et al. 2003). Persistence of RB in the animal's system depends on the dose, species, size and tissue marked (Weerakoon et al. 2013). In small mammals comparable to rats, a dose over $15 \mathrm{mg} / \mathrm{kg}$ has been shown to persist in vibrissae at least 10 weeks post-ingestion (Fisher 1999).

In wildlife management programmes, bait markers have traditionally been used to quantify bait acceptance and uptake by a species (Purdey et al. 2003; Elliott et al. 2015). However they can also be incorporated into palatable food and used as an economical means to monitor and trace small mammal movements between sites that are vulnerable to reinvasion (Purdey et al. 2003; King et al. 2011). Detecting directional movements by individuals can help create a better understanding of dispersal capabilities and motivations of invasive rat species. In turn, this information can advise island biosecurity approaches to reduce the frequency and magnitude of reinvasion events. In the context of island reinvasion from specific sites, RB can be used as a tool to determine routes of invasion. Food containing RB is distributed on site $\mathrm{A}$, the suspected source site, and subsequent kill trapping is undertaken 
at site $\mathrm{B}$, the sink site. If traces of $\mathrm{RB}$ consumption are detected in animals trapped at site $\mathrm{B}$, site $\mathrm{A}$ is confirmed as a source of reinvasion because it is the only location where animals could have ingested the bait with RB. Our aim was to use this method to confirm suspected ship rat reinvasion routes between islands in the Great Barrier Island area, Hauraki Gulf, in northern New Zealand.

\section{Methods}

\section{Study site}

The Great Barrier Island (Aotea) group, consisting of 13 islands larger than 5 ha (c. 28,500 ha; $36^{\circ} 11^{\prime} 48.84^{\prime \prime} \mathrm{S}, 175^{\circ} 24^{\prime} 58.80 " \mathrm{E}$; Figure 1), is situated $95 \mathrm{~km}$ north-east of Auckland. The main island (c. 27,400 ha) is inhabited with a permanent human population of just under one thousand (Statistics New Zealand 2013) and home to threatened endemic avian species, including tomtits (Petroica macrocephala) and red-crowned kakariki (Cyanoramphus novaezelandiae) at low densities. Invasive mammals present on the main island include ship rats, kiore, house mice (Mus musculus), rabbits (Oryctolagus cuniculus) and feral cats (Felis catus) (Ogden \& Gilbert 2009).

Our research focused on western island groups around Port Fitzroy: Motu Kaikoura and the Broken Islands, where predominantly ship rat invasion via swimming from Great Barrier Island was suspected. Motu Kaikoura (530 ha; $36^{\circ} 10^{\prime} 40.48^{\prime \prime} \mathrm{S}, 175^{\circ} 19^{\prime} 28.41^{\prime \prime} \mathrm{E}$; Figure 1) is an uninhabited island situated $80 \mathrm{~m}$ from Great Barrier at the nearest point across the Man-of-War Passage (Figure 1a). Two aerial applications of bait containing rodenticide brodifacoum were applied in 2008 with the intention to eradicate ship rats and kiore (Motu Kaikoura Trust 2011). However, ship rats and kiore were detected again in early 2009, with genetic evidence suggesting at least some of these were survivors of the eradication attempt, indicating it had failed (Fewster et al. 2011). Since then, populations of both species of rat have been reported across the entire island and are intermittently controlled by bait stations and traps (W. Scarlett pers. comm.). The Broken Islands (c. 125 ha; 36 $\left.13^{\circ} 17.50^{\prime \prime} \mathrm{S}, 175^{\circ} 18^{\prime} 14.73^{\prime \prime} \mathrm{E}\right)$ are made up of four islands, the closest island being within $300 \mathrm{~m}$ from Great Barrier Island (Figure 1a). A successful ship rat eradication using aerial application of brodifacoum bait was undertaken by Auckland Council in 2009. As the islands suffer from ship rat reinvasions, biosecurity control and surveillance measures on the island group consist of rodent kill traps and brodifacoum bait placed within bait stations along the coastline of all islands. Kill traps are checked three times per year in addition to a rodent-detecting dog being run over the islands (Gsell et al. 2010). On average, five to six ship rats swim to the Broken Island group each year and ship rats have been trapped on all four islands. Genetic analysis suggests the rats originate from Great Barrier Island, raising the strong possibility that the rats are accessing the islands by swimming, rather than as stowaways on boats (Auckland Council unpubl. data).

Two possible reinvasion source sites on Great Barrier Island were selected based on their proximity to the offshore
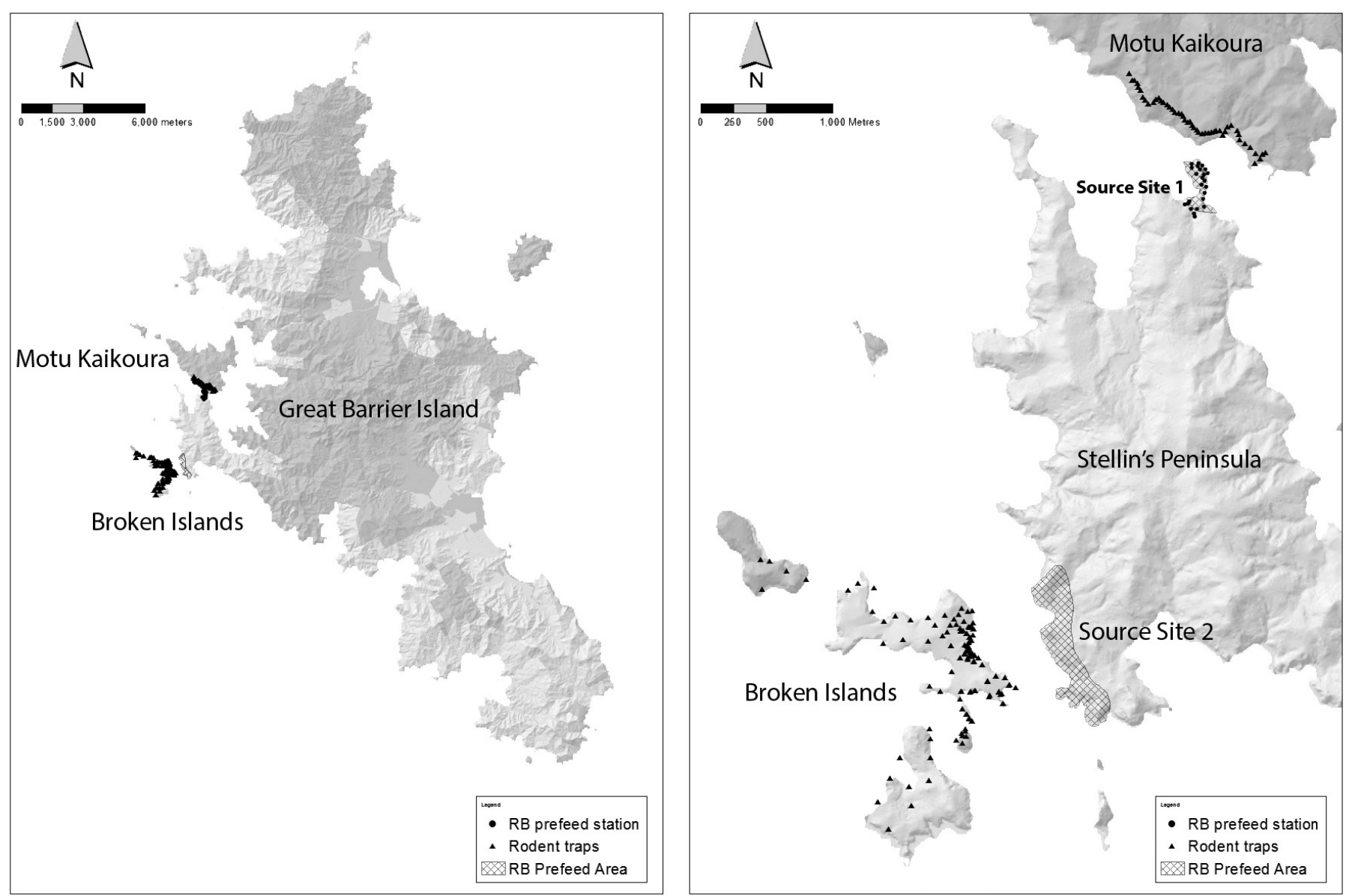

Figure 1: (a) Map of Great Barrier Island with Motu Kaikoura and Broken Islands; and (b) map of study sites indicating source sites 1 and 2 on Stellin's Peninsula baited with Rhodamine B baits and rat kill trap locations on Motu Kaikoura and Broken Islands. 
islands. Both were located on private land owned by Sven Stellin, henceforth referred to as Stellin's peninsula (c. 809 ha; $36^{\circ} 12^{\prime} 35.04^{\prime \prime S}, 175^{\circ} 19^{\prime} 19.64^{\prime \prime E}$; Figure 1b). The vegetation consists of naturally regenerating, low lying manuka (Leptospermum scoparium) and kanuka (Kunzea ericoides) scrub with invasive gorse (Ulex europaeus) and a sporadic distribution of broadleaf seedlings throughout the area. Source site 1 was located on the northern tip of Stellin's peninsula (c. 4 ha; Figure 1b) and source site 2 was located on the southwestern coast of Stellin's peninsula (c. 30 ha; Figure 1b).

\section{Rhodamine B bait distribution}

Sixteen kg of non-toxic cereal pellet baits (PestOff Possum Pre Feed; Animal Control Products Ltd., Whanganui) were soaked until surface-coated with Rhodamine B biomarker at $4 \%$ concentration ( $200 \mathrm{~g} \mathrm{RB}$ dissolved in $5 \mathrm{~L}$ water). On source site 1, bait was distributed on 18th-19th December 2012. Two people walked lines 3-5 $\mathrm{m}$ apart hand distributing bait pellets over 4 ha at an approximate density of $4 \mathrm{~kg} / \mathrm{ha}$. Additional live-trapping (Tomahawk 201 collapsible single door live traps, Wisconsin, USA) was undertaken with 25 traps spaced at 50 metres apart on 18th-20th December 2012 to estimate rat density and rate of bait uptake. On source site 2, bait was distributed on 16th-17th January 2013. Three people walked lines $50 \mathrm{~m}$ apart hand distributing bait pellets over 21 ha at an approximate density of $1.6 \mathrm{~kg} / \mathrm{ha}$. No live-trapping took place.

\section{Trapping}

Kill trapping was carried out on Motu Kaikoura on 13-20 January 2013 (4 weeks post-baiting) and 8-13 February 2013 ( 8 weeks post-baiting). The trap-line was $1.58 \mathrm{~km}$ in length on the south-western coastal region of the island (Figure 2) with 50 wooden 'motels' placed approximately 25 m apart (Russell et al. 2008b). Each motel contained two Victor Professional snap traps baited with peanut butter and traps were checked daily during the monitoring periods. Kill traps on the Broken Islands were checked on 7 and 21 March 2013 as part of a trap service which occurs three times a year. 100 'motels', containing two Victor Professional snap traps, two bait pins and a tracking tunnel, are located at key reinvasion points and in preferred rodent habitat along the coastline of all islands.

Trapped rats were identified to species, examined for external RB staining in the pelage and vibrissae were plucked from all carcasses with no obvious stains in pelage hairs. Standard morphometrics (head-body length(HBL), tail length (TL), and weight) of trapped rats were recorded and individuals were subsequently dissected to expose the gastrointestinal (GI) tract. Block out fabric was used to cover the rat while a UV lamp was used to check for orange fluorescence which would indicate recent consumption of RB (Fisher 1999). Vibrissae were plucked and retained for future analysis by fluorescence microscopy. While vibrissae grow more rapidly than other hair types, not all vibrissae grow continuously (Purdey et al. 2003), therefore between 15 and 25 vibrissae were plucked per rat, ensuring the bulbs were removed intact. Vibrissae were mounted on microscope slides $(26 \times 76 \mathrm{~mm})$, using antifadent mountant solution (Citifluor Ltd., London) and coverslips $(22 \times 50 \mathrm{~mm})$. In the field, clear nail polish was applied on the edge of the coverslip as a sealant to prevent the mountant from drying out.

\section{Rhodamine B detection}

Presence or absence of RB in vibrissae was determined by identifying fluorescent orange bands using fluorescence microscopy techniques described by Fisher(1999). Microscopy was carried out using a Leica DMRE fluorescence microscope fitted with an N2.1 epifluorescence filter (Leica microsystems, Wetzlar, Germany). Vibrissae were observed under green light $(\lambda=580 \mathrm{~nm})$. AnalySIS Life Science Research software (Olympus Soft Imaging Solutions Gmbh, Münster, Germany) was used to observe the camera view of the samples. Colour mode was set to standard, gain $=1$, resolution $=1300 \times 1030$, 4 shots, binning $=3 \times 3$ scaled, exposure time $=200 \mathrm{~ms}$. RB fluorescence had to be distinguished from natural fluorescence and other residues on the slide. If distinguished RB bands were detected in $>20 \%$ vibrissae samples of an individual rat, $R B$ presence $(\mathrm{RB}+)$ was recorded for the individual.
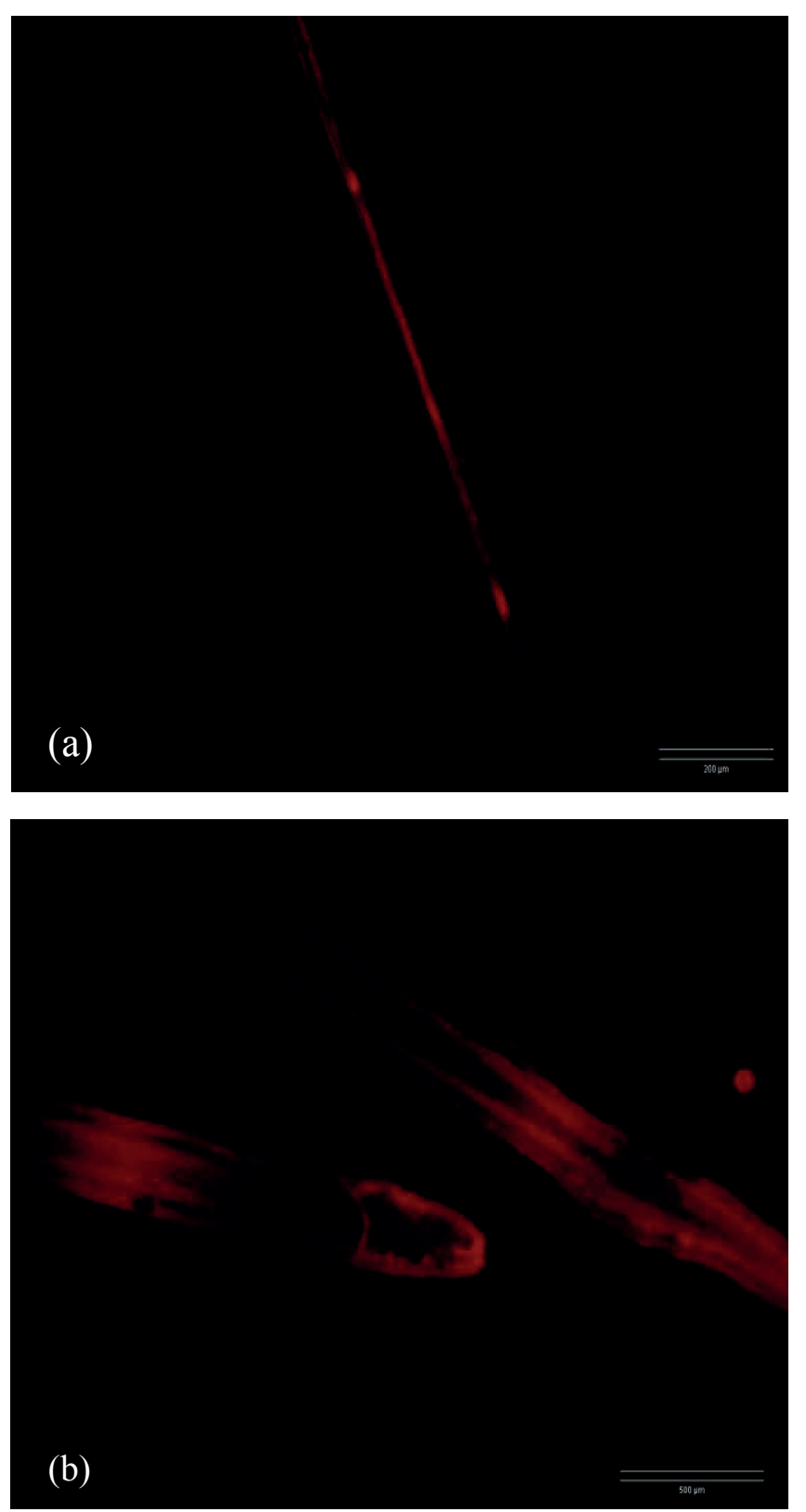

Figure 2. (a) Multiple band markings in a whisker from sequential ingestion of RB baits by a male ship rat caught on Motu Kaikoura in January and (b) singular band markings on two vibrissae close to the root of the hair indicating recent $\mathrm{RB}$ digestion by a male ship rat caught on Motu Kaikoura in February. 
For a positive control, three laboratory Norway rats were offered two, five and ten RB dyed bait pellets (4\% solution on bait) respectively on one night, 11 June 2013. We assumed there would be no significant difference in RB uptake between Norway rats, ship rats and kiore for our study. Normal diet was fed for 14 days afterward. Rats were euthanised on 25 June and approximately half of total vibrissae were plucked, prepared and examined under fluorescence microscopy as described.

\section{Results}

No rats were caught during live-trapping at source site 1 on Stellin's Peninsula. A total of 41 individuals were caught over two trapping sessions on Motu Kaikoura (Table 1). Ship rats were the predominant species, but two kiore (1 male in January, 1 female in February) were also caught. A total of four ship rat individuals were caught over one trapping session on the Broken Islands (Table 1). Ship rats less than $120 \mathrm{~g}$ and with a HBL less than $160 \mathrm{~mm}$ were classified as juveniles (Russell et al. 2009b), while all others were classed as adult rats with more male than female ship rats being trapped (Table 1).

Of the 26 ship rats caught on Motu Kaikoura in January, one juvenile ship rat male (111 g; HBL: $163 \mathrm{~mm}$ ) was RB+ (Figure 2a). Of the 13 ship rats caught on Motu Kaikoura in February, one adult ship rat male (209 g; HBL: 194) was $\mathrm{RB}+$ (Figure 2b).

Of the four ship rats caught on the Broken Islands in March, all male, three carcasses were in suitable condition to retrieve. Two carcasses were identified as RB + from red colouration in their coat, which was confirmed by analysis of vibrissae. The third carcass was identified as RB- by analysis of vibrissae.

Control laboratory Norway rats were offered different amounts of RB dyed bait pellets on a single occasion; however, all individuals consumed two pellets each. Total number of vibrissae sampled per control individual was between 15 and 20. For each individual, proportion of total $\mathrm{RB}+$ vibrissae out of total vibrissae ranged between 0.50 to 0.70 (Table 2), with an average of 0.58 ( $2 \mathrm{dp}$ ) marked with $\mathrm{RB}$.

Table 1. Total number of ship rats collected from traps on Motu Kaikoura and the Broken Islands in 2013.

\begin{tabular}{lccc}
\hline & \multicolumn{2}{c}{ Motu Kaikoura } & Broken Islands \\
\hline Month & Jan & Feb & Mar \\
Male & 14 & 11 & 4 \\
Female & 12 & 2 & 0 \\
$\%$ Juvenile & $35 \%$ & $33 \%$ & $0 \%$ \\
\hline
\end{tabular}

Table 2. Number of vibrissae examined for each control individual, showing proportion of $\mathrm{RB}+$ vibrissae per individual.

\begin{tabular}{llll}
\hline Control ind. & $\begin{array}{l}\text { Total } \\
\text { vibrissae }\end{array}$ & $\begin{array}{l}\text { RB+ } \\
\text { vibrissae }\end{array}$ & $\begin{array}{l}\text { RB+/ } \\
\text { individual }\end{array}$ \\
\hline $\mathbf{1}$ & 15 & 8 & 0.53 \\
$\mathbf{2}$ & 18 & 9 & 0.50 \\
$\mathbf{3}$ & 20 & 14 & 0.70 \\
\hline Average & 17.7 & 10.3 & 0.576 \\
\hline
\end{tabular}

\section{Discussion}

Our analysis confirmed a reinvasion pathway between Stellin's Peninsula on Great Barrier Island and the neighbouring island groups of Motu Kaikoura and the Broken Islands, with RBmarked individuals shown to have made crossings of at least $80 \mathrm{~m}$ of water. Mammalian dispersal has been widely studied and it has been hypothesised that dispersal is a response to various proximate and ultimate factors such as resource and mate competition, and avoiding inbreeding depression (Krebs 2013). Two important types of dispersal were distinguished by Lidicker (1975): presaturation dispersal, which occurs in the absence of population pressure; and saturation dispersal, which occurs when a population is at high density. Live trapping failure on the Stellin's Peninsula simultaneous to biomarker broadcast suggests that local population density was not high, signifying presaturation dispersers. Lidicker (1975) hypothesised that presaturation dispersers were individuals of good condition, male or female, seeking higher quality home sites. The regenerating manuka and kanuka scrub on Stellin's Peninsula is likely to be low quality habitat for rats which may drive saturation dispersal to seek higher quality habitats, even over a water barrier to neighbouring islands.

While Lidicker(1975) suggests that presaturation dispersal is not sex-biased, all RB + individuals in this 2013 study were male. Although in this instance the sample size is small, male-biased dispersal has been noted in other small mammal populations (Hansson 1991; Lawson Handley \& Perrin 2007). Russell et al. (2009a) recorded only large male ship rats swimming to Goat Island and King et al. (2011) documented juvenile male-biased dispersal into a forest fragment posteradication of the local population in the Waikato. Following the 2008 eradication attempt on Motu Kaikoura, rats were detected in early 2009 with the majority being male and suspected to be swimmers (H. Doig pers. comm.). These reinvasion events likely reflect one-off dispersal life history events for the individuals, rather than simply extensions of, or movements within, home-ranges, and this is supported by genetic evidence distinguishing pre-existing populations (Fewster et al. 2011). Wolff (2007) suggested that juvenile male dispersal has evolved to prevent inbreeding and is incited by the presence of female relatives. This type of dispersal was distinguished as natal dispersal, and is common in small mammals and is strongly sex selective towards males (Krebs 2013), whereas in contrast breeding dispersal occurs in adults after breeding. The prevalence of male dispersers in 2013 might therefore reflect a natal saturation dispersal. In contrast in early 2014 following a rat irruption on the main Great Barrier Island, the dispersal of rats to the Broken Islands was five times higher than normal, and for the first time dominated by females (Auckland Council unpubl. data). This event might instead reflect non-natal saturation dispersal. Future studies investigating the behavioural and evolutionary causes and drivers for dispersal by ship rats via swimming would provide more information about the invasion ecology of this highly destructive pest species.

On average RB was detected in 0.58 of total vibrissae taken from control Norway rats that each consumed two pellets on one discrete occasion. This finding is consistent with laboratory rat trials by Purdey et al. (2003) (R. norvegicus) and Weerakoon et al. (2013) (R. rattus) in which $50 \%$ and $51 \%$ (respectively) of sampled vibrissae tested positive for $\mathrm{RB}$ under fluorescence microscopy. These percentages reflect the fact that not all vibrissae are growing at the same time and 
rate thus not incorporating the $\mathrm{RB}$ in the hair shaft (Purdey et al. 2003). Therefore, it is important to take a sufficient sample from each individual to avoid false negatives if, by chance, too many non-growing vibrissae are included. Weerakoon et al. (2013) found that even with very low dosages of RB $(3.9 \mathrm{mg} / \mathrm{kg})$, as few as 5 vibrissae are required to ensure $95 \%$ certainty that a RB marking, if it is present, will be detected using fluorescence microscopy. Where animal welfare is a concern, for example where subject animals are released live, sampling large numbers of vibrissae may be undesirable as vibrissae are essential for sensory input (Brecht et al. 1997). In this case, guard hairs may be a viable alternative where analysis by fluorescence microscopy is intended; however, a larger sample of hairs would be required as guard hairs have limited vasculature and a longer resting phase resulting in a lower probability of marking the hair at the time of RB ingestion (Weerakoon et al. 2013). In our field study, between 15 and 25 vibrissae per trapped individual were mounted and examined. RB fluorescence was at times problematic to distinguish from natural fluorescence and other irregularities in the hair shaft, an issue also experienced by Weerakoon et al. (2013), most likely due to the closer detail of examination that fluorescence microscopy allows. Weerakoon et al. (2013) marked a hair as indeterminate if they were unable to distinguish between natural and RB fluorescence, whereas in this study it was marked as RB negative.

Persistence of $\mathrm{RB}$ has been examined with varying conclusions derived depending on dose and species (Fisher 1999; Purdey et al. 2003; Fisher \& Tremblay 2005). Systemic markings in the hair and claws of animals have been shown to exhibit greater persistence compared with external markings such as in the GI tract, urogenital areas, teeth and paws (Fisher 1999). Fourteen days after RB consumption, control Norway rat vibrissae exhibited fluorescent bands at varying positions along the shaft, most often close to the root of the hair. This suggests that RB is likely to still be detectable in some hairs up to several months after initial consumption. The vibrissae of the $\mathrm{RB}+$ ship rat individuals from the Broken Islands showed fluorescent bands farther away from the root indicating that the first RB feeding event occurred more than 14 days prior. The precise moment of consumption cannot be determined from this study, however bait was distributed in January and rats were caught two months later in March, putting minimum persistence at 10 weeks. Fisher(1999) found persistence of systemic markers is at least 10 weeks in small mammals such as rabbits and beavers and Rahelinirina et al. (2010) determined that $R$. rattus were still marked with RB three months after baiting. RB marking is likely to persist in rat vibrissae for several months post-consumption depending on growth rate, before eventually disappearing due to natural processes of wear, growth and shedding (Lindsey 1983) which compromise intrinsic persistence.

Biomarkers are commonly used to test bait uptake (Fisher 1999), but also have been used to cost-effectively monitor occasional animal movements between key sites (Purdey et al. 2003; Mohr et al. 2007; Rahelinirina et al. 2010; King et al. 2011). This is particularly useful at sites of low but important movement rates, such as for invasive mammals swimming or hitch-hiking (e.g. from wharves) between islands. In this context, chemical biomarkers complement existing tools such as physical (e.g. ear-tags) or genetic (e.g. microsatellite) markers, especially in cases where these methods might fail, e.g. low catchability of individuals for physical marking or high genetic similarity preventing genetic assignment.
Disadvantages of chemical biomarkers include low precision information as it is not possible to determine the exact source location of the chemically marked animals, uptake rates of bait within the population or characteristics of source populations. In spite of this, biomarkers may be particularly powerful for narrowing down source sites where a sink site suffers constant reinvasion - an ongoing problem in maintaining pest-free island status (Russell et al. 2009a). The eradications on Motu Kaikoura and the Broken Islands induced a sink effect whereby reinvasion was inevitable due to high ecological connectivity within a wider meta-population on Great Barrier Island (Russell et al. 2009b). Although work prior to the eradications suggested a lack of genetic connectivity among some islands (Fewster et al.2011), priority effects probably masked potential connectivity (Fraser et al.2015). Unless "eradication units" are isolated from reinvasion, high reinvasion rates may undermine eradication efforts (King et al. 2011). While anticipated, this study showed that Motu Kaikoura and the Broken Islands are not separate eradication units, but part of the Great Barrier Island group unit. For eradications to be successful, local populations that are not complete eradication units have to be eradicated simultaneously (Abdelkrim et al. 2010). This implies that Great Barrier Island will need to undergo a large-scale eradication operation to prevent reinvasion to surrounding islands. Until then, identified reinvasion source sites could be baited with toxin as a pre-emptive measure to reduce reinvasion rates (Russell et al. 2008b), although the benefits relative to cost of such an action in preventing island reinvasion require further investigation.

\section{Acknowledgements}

Thanks to Sven Stellin and Motu Kaikoura Trust for land access permission. Thanks to Imogen Bassett, John Innes and a reviewer for comments on the work, and Julian Emsley for fieldwork assistance. This work was supported by a University of Auckland summer studentship to AB and with Animal Ethics permit R1061.

\section{References}

Abdelkrim J, Byrom AE, Gemmell NJ 2010. Fine-scale genetic structure of mainland invasive Rattus rattus populations: implications for restoration of forested conservation areas in New Zealand. Conservation Genetics 11: 1953-1964.

Atkinson IAE 1985. The spread of commensal species of Rattus to oceanic islands and their effects on island avifaunas. In: Moors PJ ed Conservation of island birds. ICBP Technical Publication No. 3. Pp. 35-81.

Bassett IE, Cook J, Buchanan F, Russell JC 2016. Treasure Islands: biosecurity in the Hauraki Gulf Marine Park. New Zealand Journal of Ecology 40: 250-266.

Brecht M, Preilowski B, Merzenich MM 1997. Functional architecture of the mystacial vibrissae. Behavioural Brain Research 84: 81-97.

Clout MN, Russell JC 2006. The eradication of mammals from New Zealand islands. In: Koike F, Clout MN, Kawamichi M, De Poorter M, Iwatsuki K eds Proceedings of the international conference on assessment and control of biological invasion risks. Gland, Switzerland and Cambridge, UK, IUCN. Pp. 127-141. 
Elliott GP, Greene TC, Nathan HW, Russell JC 2015. Winter bait uptake trials and related field work on Antipodes Island in preparation for mouse (Mus musculus) eradication. DOC Research and Development Series 345. Wellington, Department of Conservation. $34 \mathrm{p}$.

Fewster RM, Miller SD, Ritchie J 2011. DNA profiling-a management tool for rat eradication. In: Veitch CR, Clout $\mathrm{MN}$, Towns DR eds Island invasives: eradication and management. IUCN, Gland, Switzerland. Pp. 426-431.

Fisher P 1999. Review of using Rhodamine B as a marker for wildlife studies. Wildlife Society Bulletin 27: 318-329.

Fisher P, Tremblay L 2005. A practical bait marker for brushtail possums - whisker marking by Rhodamine B. 13th Australasian Vertebrate Pest Conference Proceedings. Wellington, New Zealand, Manaaki Whenua Press, Landcare Research. Pp. 63-68.

Fraser CI, Banks SC, Waters JM 2015. Priority effects can lead to underestimation of dispersal and invasion potential. Biological Invasions 17: 1-8.

Gsell A, Innes J, de Monchy P, Brunton D 2010. The success of using trained dogs to locate sparse rodents in pest-free sanctuaries. Wildlife Research 37: 39-46.

Hansson L 1991. Dispersal and connectivity in metapopulations. Biological Journal of the Linnean Society 42: 89-103.

Howald G, Donlan C, Galván JP, Russell JC, Parkes J, Samaniego A, Wang Y, Veitch D, Genovesi P, Pascal M, Saunders A, Tershy B 2007. Invasive rodent eradication on islands. Conservation Biology 21: 1258-1268.

King CM, Innes JG, Gleeson D, Fitzgerald N, Winstanley T, O'Brien B, Bridgman L, Cox N 2011. Reinvasion by ship rats (Rattus rattus) of forest fragments after eradication. Biological Invasions 13: 2391-2408.

Krebs CJ 2013. Population fluctuations in rodents. Chicago, USA, Chicago University Press. 320 p.

Lawson Handley LJ, Perrin N 2007. Advances in our understanding of mammalian sex-biased dispersal. Molecular Ecology 16: 1559-1578.

Lidicker WZ Jr 1975. The role of dispersal in the demography of small mammals. In: Golley FB, Petrucewicz K, Ryskowski L eds Small mammals: their productivity and population dynamics. Cambridge, UK, Cambridge University Press. Pp. 103-134.

Lindsey GD 1983. Rhodamine B: a systemic fluorescent marker for studying mountain beavers Aplodontia rufa and other animals. Northwest Science 57: 16-21.

Mohr K, Leirs H, Katakweba A, Machang'u R 2007. Monitoring rodents movements with a biomarker around introduction and feeding foci in an urban environment in Tanzania. African Zoology 42: 294-298.
Motu Kaikoura Trust 2011. History and philosophy. New Zealand, Motu Kaikoura Trust. www.motukaikoura.org. nz/history.htm. (accessed 10 February 2013).

Ogden J, Gilbert J 2009. Prospects for the eradication of rats from a large inhabited island: community based ecosystem studies on Great Barrier Island, New Zealand. Biological Invasions 11: 1705-1717.

Purdey DC, Petcu M, King CM 2003. A simplified protocol for detecting two systemic bait markers (Rhodamine B and iophenoxic acid) in small mammals. New Zealand Journal of Zoology 30: 175-184.

Rahelinirina S, Duplantier JM, Ratovonjato J, Ramilijaona O, Ratsimba M., Rahalison L 2010. Study on the movement of Rattus rattus and evaluation of the plague dispersion in Madagascar. Vector-borne and zoonotic diseases 10: 77-84.

Russell JC,Abdelkrim J, Fewster RM2009a. Early colonisation population structure of a Norway rat island invasion. Biological Invasions 11: 1557-1567.

Russell JC, Beaven BM, MacKay JW, Towns DR, Clout MN 2008a. Testing island biosecurity systems for invasive rats. Wildlife Research 35: 215-221.

Russell JC, Mackay JW, Abdelkrim J 2009b. Insular pest control within a metapopulation context. Biological Conservation 142: 1404-1410.

Russell JC, Towns DR, Clout MN 2008b. Review of rat invasion biology: implications for island biosecurity. Science for Conservation 286. Wellington, Department of Conservation. 53 p.

Statistics New Zealand 2013. QuickStats about a place: Great Barrier Local Board Area. www.stats.govt.nz/ Census/2013-census/profile-and-summary-reports/ quickstats-about-a-place.aspx (accessed 25 May 2015).

Towns DR, Broome KG 2003. From small Maria to massive Campbell: forty years of rat eradications from New Zealand islands. New Zealand Journal of Ecology 30: 377-398.

Towns DR, Atkinson IAE, Daugherty CH 2006. Have the harmful effects of introduced rats on islands been exaggerated? Biological Invasions 8: 863-891.

Weerakoon MK, Price CJ, Banks PB 2013. Hair type, intake, and detection method influence Rhodamine B detectability. The Journal of Wildlife Management 77: 306-312.

Wolff JO 2007. Social biology of rodents. Integrative Zoology 2: 193-204. 